\title{
Information Dissemination
}

National Cancer Institute

\section{Source}

National Cancer Institute. Information Dissemination. NCI Thesaurus. Code C16732.

For information to be useful, not only does it need to be made available at the right time to those who need it such as policy makers, program planners, and health professionals, and patients but it has to be in the right form. Information Dissemination includes both research into means of information distribution and the actual distribution of information. 